\title{
A Novice Approach of Designing CMOS Based Switchable Filters for ASP Applications
}

\author{
Rajinder Tiwari, G R Mishra \\ Department of Electrical and Electronics Engineering, Amity University, Lucknow, India
}

\begin{tabular}{l}
\hline \hline Article Info \\
\hline Article history: \\
Received May 30, 2015 \\
Revised Jul 3, 2015 \\
Accepted Jul 26, 2015 \\
\hline
\end{tabular}

\section{Keyword:}

Bandpass filter (BPF)

Capacitive loading

CMOS filters

Low pass filter (LPF)

pSpice simulation software

Switchable filters

Tunable filter

\begin{abstract}
A switchable filter can be designed and fabricated with the desired range and parameters, materials say quartz substrate for RF MEMS based applications. The mathematical modeling of the resonators using the desired characteristics of the capacitive coupled filters can be implemented with low insertion loss. In order to design this filter, one can employ a PIN diode along with a semi-lumped resonator. This PIN diode has been used so as it performs the function of electronic switching i.e. the activating and deactivating the filter circuit action without any compromise in the overall performance of the circuit. These filters circuit are designed and implemented in a way so that it can accommodate the external quality factor in order to ensure a good impedance match at each band of operation. The most dominant parameters and characteristics of the second order switchable filter realization. In this work, the author has put an effort to discuss the most desired parameters of the various switchable filters. In these filter circuits, CMOS devices has been used to design because of their well accepted features i.e. low power loss and requirement of low input signal for operation in addition to other ones. The performance of the proposed CMOS based switchable filters has been discussed with its simulated results that have been carried out by using pSpice software with 0.18 micron technology. The insertion loss of this circuit is with the acceptable limits i.e. $2.9 \mathrm{~dB}$ and a tenability within two desired frequencies.
\end{abstract}

Copyright (C) 2015 Institute of Advanced Engineering and Science. All rights reserved.

\section{Corresponding Author:}

Rajinder Tiwari,

Department of Electrical and Electronics Engineering,

Amity University, Lucknow

Near Malhore Railway Crossing, Gomti Nagar Extension, Lucknow (Uttar Pradesh)- 226028, India.

Email: trajan@rediffmail.com

\section{INTRODUCTION}

A PIN diode plays a dominant role in the functioning of the RF systems that use the time division duplexing (TDD). In this system, the switching element employed has poor selectivity of the frequency within the specified band of the signals. This purpose can be obtained with the cascading of a band pass filter in addition to the switching module. But with this methodology, the overall loss and the size of the filter circuit thereby increases. This limitation of the system can be easily avoided simply by using switching element with a bandpass filter so as to integrate the two components. Thus, with this arrangement the resulting switchable filter will have the desirable switching characteristics of the switching element as well as the high selectivity of the bandpass filter. This approach leads to a more compact design with lower losses [1]-[5]. The tunable filters are the most essential components for reconfigurable front-ends since they allow the use of a single component as opposed to a switched-filter bank, thereby reducing the system size and complexity. However, since they are placed between the antenna and low-noise amplifier, they must exhibit very low loss and high linearity, especially in today's crowded RF environments. The major challenge of multi-mode RF circuits lies in the integration of RF chips and the passive components with different 
frequency bands, which correspond to different operating modes. Conventional multi-mode RF circuits that duplicate the front-end components for each frequency band have band-separated transmitter and receiver interfaces. Recently, the architectures that integrate the RF transceiver of various frequency bands have been studied to optimize the size and power consumption of RF chips [2]-[10].

However, with regard to the distortion problem in the RF back-end circuit of the concurrent transceiver, the switchable bandpass filter is more promising solution. Bandpass filters with controllable center frequency have been investigated extensively. The filter bank structure includes fixed filters of which each has its own center frequency, as well as switching networks at both input and output terminals for band selection. Continuously tuned filters, which have highly integrated structure, facilitate the use of variable capacitors, such as MEMS devices, varactor diodes or ferroelectric material, for tuning center frequencies. Explicit design procedures for tunable filter composed of varactor diode and transmission line have been presented in [11]-[15]. Moreover, switchable filter involving a resonator with the PIN diodes has been proposed to select between the bands of two specified frequencies. The recent wireless communication systems require a wide bandwidth for a high data rate i.e. an ultra-wideband (UWB) technology is very promising for future communication and radar systems. This new technology has stimulated significant effects in the R\&D based applications. However, the frequency, as a resource, is valuable and limited, so the frequency spectrum is always crowded for several purposes, which means it is full of unwanted signals when a specific operation is concerned. Nevertheless, for future cognitive radio, tunable microwave filters become more critical. Therefore, it is more desirable to electronically switch on/off a notch in an UWB BPF. For this purpose, a UWB bias network has been used for the effectively performance of the system. The bandpass filters (BPFs) are the most important components of a RF and the microwave systems based applications. This system provides a small insertion loss within the pass band and large attenuation in the stop band. Recently, dual-band BPFs have drawn a lot of attention in multi-frequency applications. This method is very effective; nevertheless, it is not the most suitable for applications using distributed resonators on a low dielectric constant substrate because the two distributed BPFs will occupy a large circuit area. Stepped impedance resonators have been found to be good candidates for dual-band BPFs. By controlling the dimensions of a stepped-impedance resonator, one can control the frequency ratio of the first two resonant modes. It has been found that the two switchable dual-band BPFs are the most desired approach in the design and implementation of the switchable filters. Most important feature of the BPFs is that they do not require additional dual-band impedance transformers. Furthermore, in order to meet the more stringent specifications of modern multifunction systems, research interest in reconfigurable BPFs has increased recently [16]-[19].

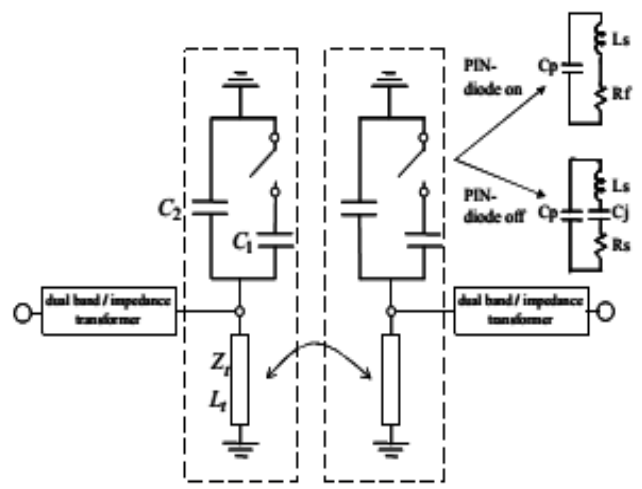

Figure 1. Filter Circuit of switchable filter with PIN diode as a switching device [20]

This methodology of the adaptive capability filter circuit has also find enormous application in the health monitoring domain, which uses a low-power radio-frequency (RF) transmitter technology. It is expected that this technique may gain more popularity in the field of homecare because of its great potential as a low-cost medical service offering high patient safety. Rapid economic and industrial development results in increased intensity in daily life, which has negative effects on people, including nervousness, anxiety, and disturbance. These emotions, along with changes in lifestyle, have made chronic cardiovascular diseases the leading adult illnesses in place of infectious diseases. The ergonomics industry has recently invested in the development of information technology engineering to improve patient safety, enhance nursing efficiency, and decrease healthcare expenses. The Figure 1 shows the schematic arrangement of the switchable filter with the PIN device that has been used as the main switching device. The body sensor network (BSN) 
technology has the capability to transfer the task of healthcare monitoring from the clinic to the healthcare center for long-term attention. According to the BSN, home telecare monitoring allows patients to examine themselves using bio-signal acquisition nodes (BANs). In this system, the user can collect the bio-signal on a bio-information node (BIN) and subsequently submit personal data to the healthcare center through the local sensor network. This system can also be employed in the intelligent healthcare systems that can found enormous applications in the monitoring of cardiovascular (CV) disease through wireless communication. The basic requirement of this system for the long-term and portable monitoring modules, is the low power, portability, miniaturization, etc should be met. Therefore, a system-on-a-chip (SOC) with very large-scale integration technology should be employed in the circuit implementation [21]-[25].

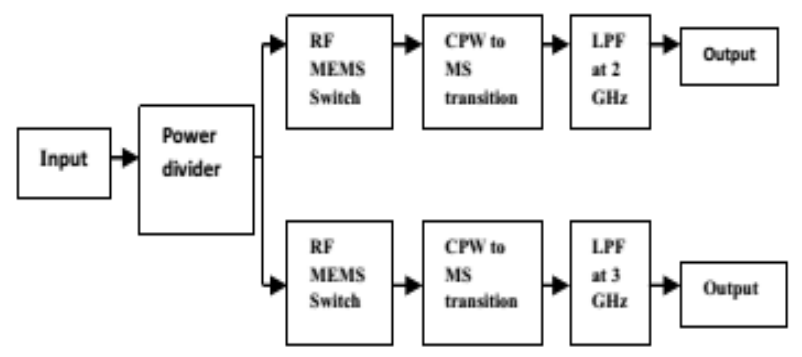

Figure 2. RF MEMS Based Switchable Low Pass Filter [26]

The above Figure 2 shows the basic schematic arrangement of the switchable RF MEMS based low pass filter. This system is basically constitutes of a Wilkinson power divider at the input section of the system which simply splits the power equally into two proportions. Then this signal is made to travel through the RF MEMS switch and transition before interacting the output modules. Finally, the output of this circuit is applied to the micro strip section of the system which operates within the desired range of the frequencies (in $\mathrm{GHz}$ range). In this system, the filter response is made switchable between two frequencies simply by using the CPW based RF MEMS switch [27]-[30].

\section{BASIC OF SWITCHABLE FILTERS}

In order to validate the design concept and the operation of the dual-band two-pole BPF with a stepped-impedance resonator has been discussed. The value of the external Q can be calculated with the help of the below equation [31]

$$
Q=\frac{R_{L} \omega_{0}}{2} \frac{\partial B}{\partial \omega} \mid \omega_{0}
$$

Where $\mathrm{B}$ is the total susceptance seen at the tap point looking into the resonator, $\mathrm{v}_{0}$ is the angular frequency and $R_{L}$ is the load impedance at the tap point seen by the resonator $\left(R_{L}\right.$ should be $50 V_{\text {in }}$ so as to eliminate the additional impedance transformer). The Figure 3 shows the schematic arrangement of the inverted-coupled BPF which is quite commonly used in the design of the high performance adaptive filters [32]-[35].

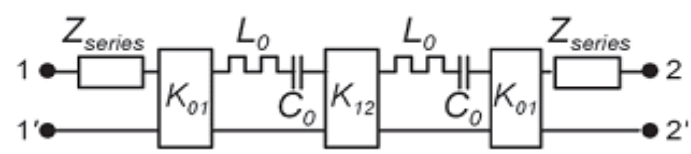

Figure 3. Inverter-coupled bandpass filter prototype [36]

$$
Y_{I N}=\frac{Z_{c}+j Z_{T} \tan \left(\theta_{c}\right)}{Z_{c}\left(Z_{T}+j Z_{c} \tan \left(\theta_{c}\right)\right)}+\frac{j \tan \left(\theta_{D}\right)}{Z_{D}}=0
$$


Where,

$$
Z_{T}=j Z_{B}\left[\frac{Z_{A} \tan \left(\theta_{A}\right)+Z_{B} \tan \left(\theta_{B}\right)}{Z_{B}-Z_{A} \tan \left(\theta_{A}\right) \tan \left(\theta_{B}\right)}\right]
$$

And,

$$
Z_{C}=\frac{Z_{e}+Z_{0}}{2}
$$

In order to achieve a compact size, the two sections of the circuit are of the same electrical length. The characteristic impedance of the narrow line is $Z_{2}$, and the characteristic impedance of the wide line is $Z_{3}$. The dimensions of the resonator control the frequency ratio of the first two passband frequencies. For a frequency ratio of 2.4 , the impedance ratio $\left(Z_{2} / Z_{3}\right)$ is 1.64 . Based on the mathematical equations, one can derive the equation for external [37]-[40] Q i.e.

$$
Q=\frac{25}{Z_{2}} \frac{A+B+C+D}{Z_{2}\left(Z_{3} \cot \theta_{3}-Z_{2} \tan \theta_{2}\right)^{2}}
$$

Where the parameters A, B, C and D can be defined as below:

$$
\begin{aligned}
& A=Z_{3}\left(\left(\theta_{2}+\theta_{4}\right) \cot \theta_{3} \sec ^{2}\left(\theta_{2}+\theta_{4}\right)-\theta_{3} \tan \left(\theta_{2}+\theta_{4}\right) \operatorname{cosec}^{2} \theta_{3}\right) \\
& \times\left(Z_{3} \cot \theta_{3}-Z_{2} \tan \left(\theta_{2}+\theta_{4}\right)\right) \\
& B=Z_{3}\left(\left(\theta_{2}-\theta_{4}\right) \cot _{3} \sec ^{2}\left(\theta_{2}-\theta_{4}\right)-\theta_{3} \tan \left(\theta_{2}-\theta_{4}\right) \operatorname{cosec}^{2} \theta_{3}\right) \\
& \times\left(Z_{3} \cot \theta_{3}-Z_{2} \tan \left(\theta_{2}-\theta_{4}\right)\right) \\
& C=\left(Z_{2}+Z_{3} \cot \theta_{3} \tan \left(\theta_{2}+\theta_{4}\right)\right) \times\left(Z_{3} \theta_{3} \operatorname{cosec}^{2} \theta_{3}-Z_{2}\left(\theta_{2}+\theta_{4}\right) \sec ^{2}\left(\theta_{2}+\theta_{4}\right)\right) \\
& D=\left(Z_{2}+Z_{3} \cot \theta_{3} \tan \left(\theta_{2}-\theta_{4}\right)\right) \times\left(Z_{3} \theta_{3} \operatorname{cosec}^{2} \theta_{3}-Z_{2}\left(\theta_{2}-\theta_{4}\right) \sec ^{2}\left(\theta_{2}-\theta_{4}\right)\right)
\end{aligned}
$$

The circuits of the various filters can be designed as per the requirement of the signal processing applications which involves the selection of the appropriate values of the dominant parameters so as to set the frequency of the resonating circuits. These dominant parameters of these circuits are $\mathrm{C}_{0}, \mathrm{~L}_{0}, \mathrm{~K}_{01}, \mathrm{~K}_{12}$, etc. which are explained properly with the help of the below mathematical behaviors of the system. This designing approach is based on the mathematical modeling of the dominant parameters of the system [41][45].

$$
\begin{aligned}
& C_{0}=\frac{\omega_{2}^{2}-\omega_{1}^{2}}{\omega_{1} \omega_{2}\left[\omega_{1} Z\left(\omega_{2}\right)-\omega_{2} Z\left(\omega_{1}\right)\right]} \\
& L_{0}=\frac{1}{\omega_{0}^{2} C_{0}} \\
& K_{01}=\sqrt{\frac{Z_{\text {source }} \Delta \omega L_{0}}{g_{0} g_{1}}} \\
& K_{12}=\Delta \omega L_{0} \sqrt{\frac{1}{g_{0} g_{1}}}
\end{aligned}
$$

Where,

$$
\begin{aligned}
& Z(\omega)=\frac{j Z_{c}^{2} \operatorname{cosec}^{2}\left(\theta_{c}\right)}{Z_{D} \cot \left(\theta_{D}\right)+Z_{c} \cot \left(\theta_{c}\right)}-j Z_{c} \cot \left(\theta_{c}\right) \\
& Z_{\text {source }}=50+Z_{\text {series }} \\
& Z_{\text {series }}=j \frac{\left(Z_{e}-Z_{0}\right)^{2} \cot ^{2}\left(\theta_{c}\right)}{4\left[Z_{D} \cot \left(\theta_{D}\right)+Z_{c} \cot \left(\theta_{c}\right)\right]}-j Z_{c} \cot \left(\theta_{c}\right)
\end{aligned}
$$


The calculated behavior of the $\mathrm{K}_{01}$ parameter can be easily realized simply by adjusting the values of the impedance of the coupled line of the circuit [46].

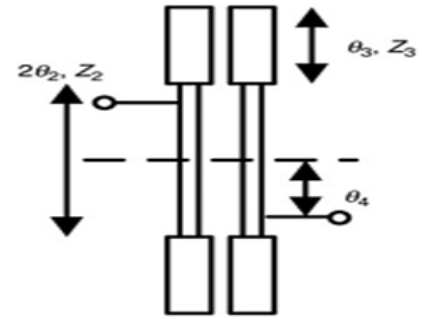

Figure 4. Schematic diagram of two-pole dual-band $\mathrm{BPF}$

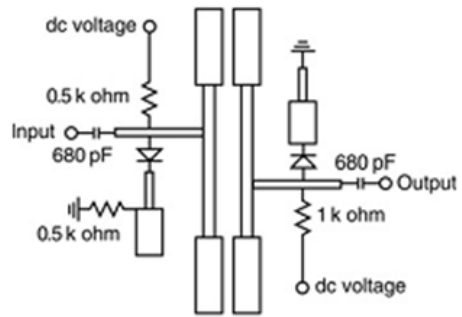

Figure 5. Schematic diagram of the first switchable dualband BPF

The Figure 4 shows the schematic diagram of the switchable dual-band BPF using the stepped impedance resonators as the active devices. In this circuit, there are two PIN diodes which are used to connect/disconnect the open-circuited stub and the short-circuited stub. The parasitic inductance is $0.7 \mathrm{nH}$. The diode also has a low capacitance of $0.15 \mathrm{pF}$ and a resistance of $3.5 \mathrm{~V}$ at $1 \mathrm{~mA}$ and $100 \mathrm{MHz}$. To switch ON the diodes, the external dc voltage is $3 \mathrm{~V}$, and the current is $1 \mathrm{~mA}$. The dc-blocking capacitance is 680 pF. The resistors of 500 and 1000 ohms are used for biasing and to provide sufficient dc-RF isolation. The above Figure 5 shows the schematic diagram of the second BPF. It is a four-pole dual-band BPF, where four stepped-impedance resonators are employed [47].
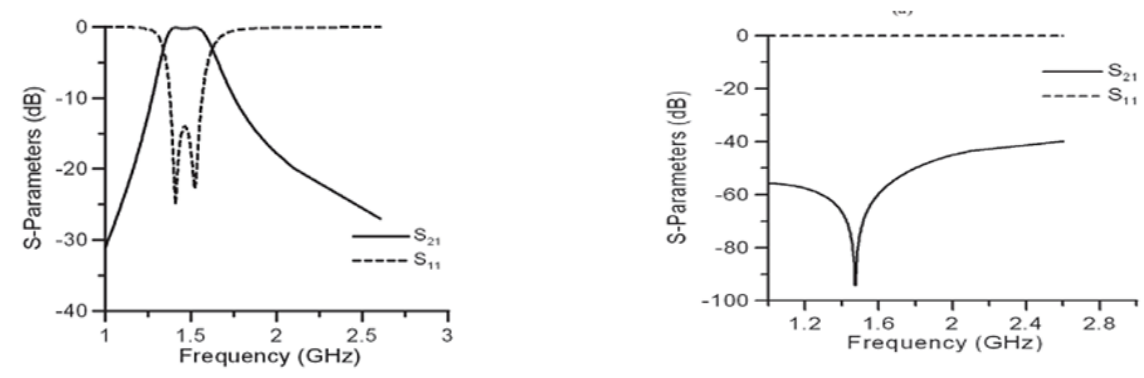

Figure 6. Simulated S-parameters of the switchable filter in (a) ON state (b) OFF state [48]

The distortion performance of the switchable filters has been discussed and the performance was evaluated in the ON state of the active device using the digital signal at the specified rate. The measured results for a lower bias voltage as compared to a higher value produce more distortions as shown in above figure 6 a \& b respectively. From these graphical analyses of the circuit, it has been found that the distortions phenomenon is more evident at higher values of input power [49].

\section{PROPOSED CMOS BASED SWITCHABLE ADAPTIVE FILTER}

The Figure 7 shows the schematic arrangement of the proposed CMOS based adaptive switchable filter, which is capable of operating in the different capacity i.e. filter region. In this circuit, the CMOS has been used as the active devices for switching purpose i.e. to connect and disconnect the sub module. This circuit has been designed to perform the role of dualband BPF, with the mathematical expression for external Q. As compared to the earlier work, this dual-band BPF does not require any additional dual-band impedance transformers. Since this circuit employs the CMOS i.e. low power devices, this adaptive switchable filter has got enormous applications in the field of biomedical signal processing, analog signal processing, etc. In addition to this, the power consumption of this filter has been found to be $8.88 \mathrm{~mW}$ under a $1.2 \mathrm{~V}$ supply voltage, whereas the transmitted output power is $-1.72 \mathrm{dBm}$ without sacrificing the required performance. The simulation work of this circuit has been performed by using pSpice software with 0.18 micron technology. The results obtained with this simulation work are quite satisfactory and are with the theoretical assumptions. This work put forward a switchable adaptive filter, which has been fabricated in a multi-layer ceramic circuit 
process to provide high integration and miniature implementation. The approach that integrates a PIN diode (using CMOS device) in a semi-lumped resonator provides a large frequency switching ratio. The proposed dual band/impedance source impedance transformer circuit offers favorable matching conditions in both passbands. The measurements so obtained with the present discussion agree closely with theoretical predictions.

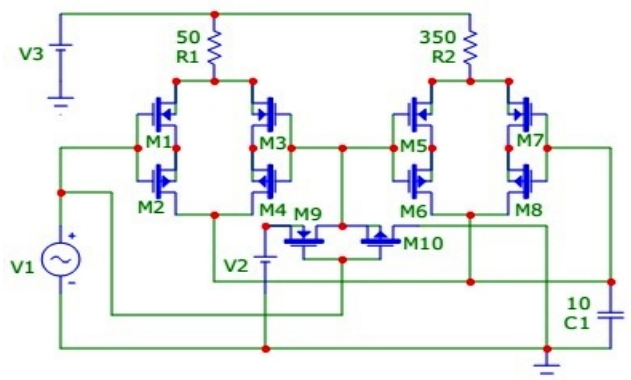

Figure 7. Proposed CMOS Based Switchable Filter

\section{SIMULATION \& EXPERIMENTAL DISCUSSION}
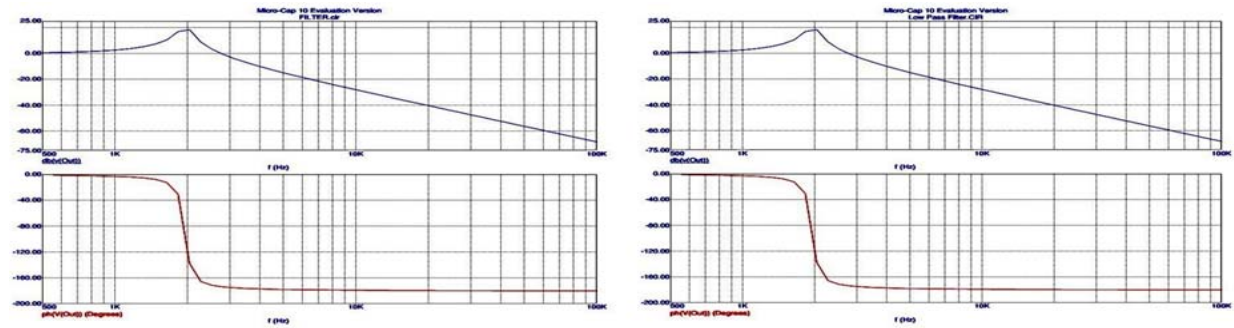

(a) AC analysis of the Proposed CMOS Switchable Filter
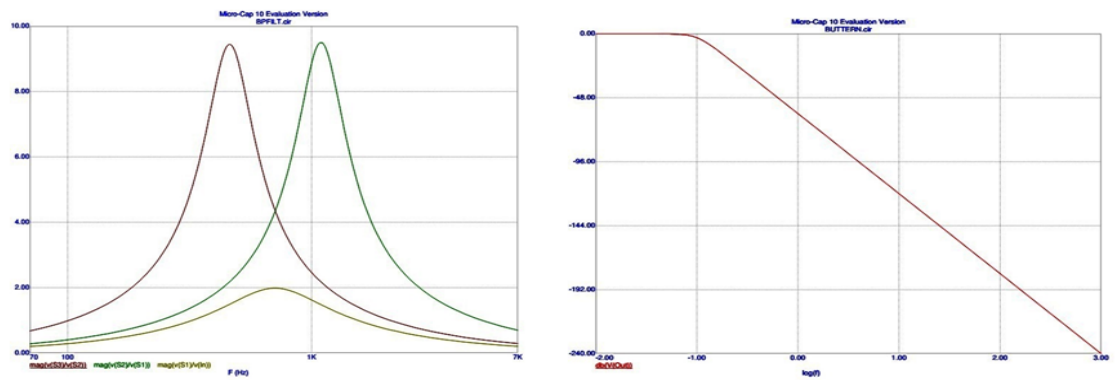

(b) Bode Plot analysis of Proposed CMOS based Switchable Filter Circuit
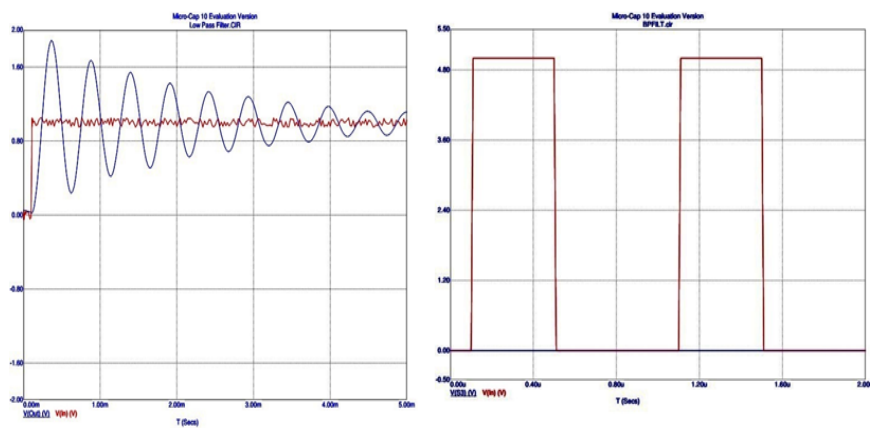

(c) Transient Analysis of Proposed CMOS based Switchable Filter Circuit

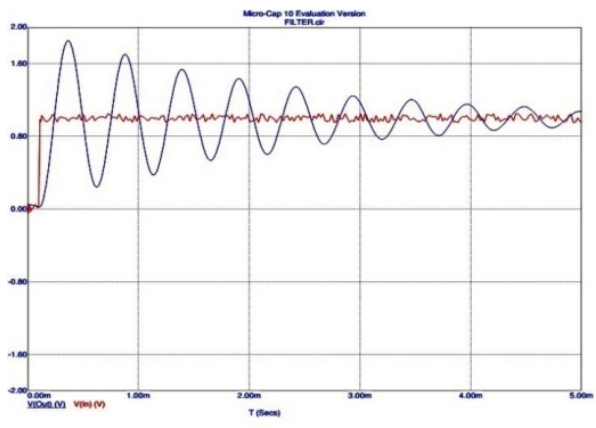

(d) Transient Analysis of Prposed CMOS based Switchable Filter with Noise

Figure 8. Simulation Results of the Performance of Proposed CMOS based Switchable Filters

A Novice Approach of Designing CMOS Based Switchable Filters for ASP Applications (Rajinder Tiwari) 
The above Figure 8(a-d) shows the simulations output results determining the performance of the proposed circuit. In this process of simulation, the most dominant behavior of the circuit has been discussed such as AC analysis, Bode plot analysis, and Transient analysis with and without the effect of the noise existing in the circuit. The results so obtained from this proposed circuit helps in determining the performance of the circuit when employed in various applications.

\section{CONCLUSION}

The performance of the proposed CMOS based switchable filter has been discussed with reference to various roles in switching the frequency of the signal using CMOS as the active switching device. In this discussion, the simulation results of the circuit have been found to be in close with the theoretical assumptions. For this simulation work, the pSpice tool has been used with 0.18 microns CMOS technology. The basic advantage of using electronic tool is that the desired components are quite easily available. The performance of the proposed CMOS based switchable filters has been discussed with its simulated results that have been carried out by using pSpice software with 0.18 micron technology. The insertion loss of this circuit is with the acceptable limits i.e. $2.9 \mathrm{~dB}$ and a tenability within two desired frequencies.

\section{ACKNOWLEDGEMENTS}

The authors are thankful to Hon'able C - VI, Mr. Aseem Chauhan (Additional President, RBEF and Chancellor AUR, Jaipur), Maj. General K. K. Ohri (AVSM, Retd.) Pro-VC Amity University, Uttar Pradesh Lucknow, Wg. Cdr. Dr. Anil Kumar, Retd. (Director, ASET), Prof. S. T. H. Abidi (Professor Emeritus), Brig. U. K. Chopra, Retd. (Director AIIT), Prof. H K Dwivedi (Director, ASAP), Prof O. P. Singh (HOD, Electrical \& Electronics Engg.) and Prof. N. Ram (Dy. Director ASET) for their motivation, kind cooperation, and suggestions.

\section{REFERENCES}

[1] Syed Haider Abbas, Hussnain Haider, Muhammad Faheem Siddique, and Awais Ahmed, "SAW Filter Modelling in Matlab for GNSS Receivers," International Journal of Electrical and Computer Engineering (IJECE), Vol. 3, No. 5, pp. 660-667, 2013.

[2] Jafar Ramadhan Mohammed, Muhammad Safder Shafi, Sahar Imtiaz, Rafay Iqbal Ansari, and Mansoor Khan, "An Efficient Adaptive Noise Cancellation Scheme Using ALE and NLMS Filters,” International Journal of Electrical and Computer Engineering (IJECE), Vol. 2, No. 3, pp. 325-332, 2012.

[3] P. W. Wong, I. C. Hunter, "Electronically Reconfigurable Microwave Bandpass Filter," IEEE Microw. Theory and Trans., Vol. 57, No. 12, 2009.

[4] Y. M. Chen, S. F. Chang, et al., "A reconfigurable bandpassbandstop filter based on varactor-loaded closed-ring resonators,” Microwave Magazine, IEEE, Vol. 10, No. 1, pp. 138-140, 2009.

[5] L. Athukorala, D. Budimir, "Frequency Tunable Microstrip Resonators and Filters,” Proc. EuMC’09, pp. 12391242, 2009.

[6] L. Athukorala, D. Budimir, “Compact dual-mode open loop microstrip resonators and filters”, IEEE Microw. And Wireless Comp. Lett., Vol. 19, No. 11, pp. 698-700, 2009.

[7] Rebeiz g. M., Entesari K., Renis I. C., et al., “TuningintoRF MEMS”, Microw. Mag., Vol. 10, No. 6, pp. 55-72, 2009.

[8] Kuo J. T., Lin H. P., "Dual-band bandpass filter with improved performance in extended upper rejection band", IEEE Trans. Microw. Theory Tech., Vol. 57, No. 4, pp. 824-829, 2009.

[9] Hong J. S., “Reconfigurable planar filters”, Microw. Mag., Vol. 10, No. 6, pp. 73-83, 2009.

[10] Dai G. L., Xia M. Y., "Design of compact dual-band switchable bandpass filter”, Electron. Lett., Vol. 45, No. 10, pp. 506-507, 2009.

[11] Zhang X. Y., Xue Q., “Novel centrally loaded resonators and their applications to bandpass filters”, IEEE Microw. Theory Tech., Vol. 56, No. 4, pp. 913-921, 2008.

[12] Tu W. H., "Compact double-mode cross-coupled microstrip bandpass filter with tunable transmission zeros”, IET Microw. Antenna Propag., Vol. 2, No. 4, pp. 373-377, 2008.

[13] Lin Y.S., Chang P.Y., Hsieh Y.S., "Compact electronically switchable parallel-coupled microstrip bandpass filter with wide stopband”, IEEE Microw. Wirel. Compon. Lett., Vol. 18, No. 4, pp. 254-256, 2008.

[14] Mokhtaari M., Bornemann J., Amari S., "Quasi-elliptic dualband filter design using stepped-impedance resonators and coupling topologies for narrow-to-wide-band applications”, IET Microw. Antenna Propag., Vol. 2, No. 8, pp. 863-870, 2008.

[15] W. Y. H Chun, J. S Hong, "Electronically reconfigurable dual-mode microstrip open-loop resonator filter”, IEEE Microw. And Wireless Comp. Lett., Vol. 18, No. 7, pp. 449-451, 2008. 
[16] J. S Hong and M. J. Lancaster, et al., "BST-varactor tunable dual-mode filter using variable Zc transmission line," IEEE Microw. And Wireless Comp. Lett., Vol. 18, No. 3, pp. 167-169, 2008.

[17] H. Shaman and J. S. Hong, "Ultra-wideband (UWB) bandpass filter with embedded band notch structures", IEEE Microw. Wireless Compon. Lett., Vol. 17, No. 3, pp. 193-195, 2007.

[18] W. D. Yan and R. R. Mansour, "Compact tunable bandstopfilter integrated with large deflected actuators", In IEEE MTT-S Int. Dig., pp. 1611-1614, 2007.

[19] Takacs, D. Neculoiu, D. Vasilache, A. Muller, P. Pons, L. Bary, P. Calmon, H. Aubert, and R. Plana, "Tunable bandstop MEMS filter for millimeter-wave applications,” Electron. Lett., Vol. 43, No. 12, pp. 675-677, 2007.

[20] H. Shaman and J.-S. Hong, "Asymmetric parallel-coupled lines for notch implementation in UWB Filters", IEEE Microw. Wireless Compon. Lett., Vol. 17, No. 7, pp. 516-518, 2007.

[21] W. T. Tu and K. Chang, "Piezoelectric transducer-controlled dual-mode switchable bandpass filter", IEEE Microw. Wireless Compon. Lett., Vol. 17, No. 3, pp. 199-201, 2007.

[22] Tu W. H., Chang K., "Piezoelectric transducer-controlled dual-mode switchable bandpass filter", IEEE Microw. Wirel. Compon. Lett., Vol. 17, No. 3, pp. 199-201, 2007.

[23] Chao S. F., Wu C. H., Tsai Z. M., Wang H., Chen C. H., "Electronically switchable bandpass filters using loaded stepped-impedance resonators”, IEEE Trans. Microw. Theory Tech., Vol. 54, No. 12, pp. 4193-4201, 2006.

[24] W. Menzel and P. Feil, "Ultra-wideband (UWB)filters with WLAN notch”, In Proc. 36th EuMC'06, pp. 595-598, 2006.

[25] J. Nath, W. M. Fathelbab, et al., "Discrete Barium Strontium Titanate (BST) Thin-Film Interdigital Varactors on Alumina: Design, Fabrication, Characterization, and Applications", Microwave Symposium Digest, 2006. IEEE MTT-S International, pp.552-555, 2006.

[26] K. Li, D. Kurita, and T. Matsui, “UWB bandpassfilters with multi notched bands”, In Proc. 36th EuMC'06, pp. 591-594, 2006.

[27] “EM User’s Manual”, ver. 10, Sonnet Software Inc., 2006.

[28] Neculoiu D., Giacomozzi F., Bary L., et al., "Compact lumped elements micromachined band-pass filters with discrete switching for 1.8/5.2 GHz applications”, Int. Semiconductor Conf., pp. 107-110, 2006.

[29] S. F. R. Chang, Wen-Lin Chen, Shuen-Chien Chang, Chi-Kang Tu, Chang-Lin Wei, Chih-Hung Chien, Cheng-Hua Tsai, J. Chen, and A. Chen, “A dual-band RF transceiver for multistandard WLAN applications”, IEEE Transaction on MTT,Vol. 53, No. 3, 2005.

[30] K. Matsuge, S. Hiura, M. Ishida, T. Kitahara, and T. Yamamoto, "Full RF module with embedded filters for 2.4 GHz and $5 \mathrm{GHz}$ dual band WLAN applications", IEEE MTT-s, Vol. 2, 2004.

[31] Chang S. F., Jeng Y. H., CHEN J. L., "Dual-band stepimpedance bandpass filter for multimode wireless LANs", Electron. Lett., Vol. 40, No. 1, pp. 38-39, 2004.

[32] H. M. Lee, C. R. Chen, C. C. Tsai, and C. M. Tsai, "Dual-band Coupling and Feed Structure for Microstrip Filter Design”, IEEE MTT-s, 2004.

[33] B. W. Kim and S. W. Yun, "Varactor-tuned dual mode bandpass filter using step-impedance microstrip lines", IEEE Trans. Microw. Theory Tech., Vol. 52, No. 4, pp. 1279-1283, 2004.

[34] Kuo J. T., Cheng H. S., "Design of quasi-elliptic function filters with a dual-passband response”, IEEE Microw. Wirel. Compon. Lett., Vol. 14, No. 10, pp. 472-474, 2004.

[35] Lee H. M., Chen C. R., Tsai C. C., Tsai C. M., "Dual-band coupling and feed structure for microstrip filter design". IEEE MTT-S Int. Digest, pp. 1971-1974, 2004.

[36] L. H. Hsieh and K. Chang, “Tunable microstrip bandpass filters with two transmission zeros”, IEEE Trans. Microw. Theory Tech., Vol. 51, No. 2, pp. 520-525, 2003.

[37] Monzon C., “A small dual-frequency transformer in two sections”, IEEE Trans. Microw. Theory Tech., Vol. 51, No. 4, pp. 1157-1161, 2003.

[38] A FCC, "Revision of Part 15 of the Commission’s Rules Regarding UltraWide-band Transmission System”, ETDocket, 98-153, 2002.

[39] H. Hashemi and A. Hajimari, "Concurrent Multiband Low-noise Amplifiers-Theory, Design, and Applications”, IEEE Transaction on MTT, Vol. 50, No. 1, 2002.

[40] Hong J. S., Lancaster M. J., “Microstrip filters for RF/microwave applications”, Wiley, New York, Vol. 8, 2001.

[41] J. S. Hong and M. J. Lancaster, "Microstrip Filters for RF/Microwave Applications”, New York: Wiley, 2001.

[42] Kai Chang, Inder Bahl, and Vijay Nair, "RF and Microwave Circuit and Component Design for Wireless Systems", John Wiley \& Son, INC. Publication, 2001.

[43] Tsai C. M., Tsai C. C., Lee S. Y., "Nonsynchronous alternatingimpedance transformer”, Asia Pacific Microwave Conf., pp. 310-313, 2001.

[44] R. Brown, G. M. Rebeiz, “A varactor-tuned RF filter”, IEEE Trans. MTT, Vol. 48, No. 7, 2000.

[45] Mahe F., Tanne G., Rius E., et al., "Electronically switchable dual-band microstrip interdigital bandpass filter for multistandard communication applications”, European Microwave Conf., 2000.

[46] J. Mitola III, "Cognitive radio forflexible mobile multimedia communications", In IEEE Int. Workshop Mobile Multimed. Comm. Dig., pp. 3-10, 1999.

[47] Kitazawa H. S., Ishizaki T., Yamada T., Nagatomi Y., “A miniaturized monolithic dual band filter using ceramic lamination technique for dual mode portable telephones”, IEEE MTT-S Int. Microwave Symp., pp. 789-792, 1997.

[48] T. S. Martin, F. Wang, and Kai Chang, "Theoretical and experimental investigation of varactor-tuned switchable microstrip ring resonator circuits", IEEE Trans. Microwave theory and Techniques, Vol. 36, 1988.

[49] M. Makimoto and M. Sagawa, "Varactor tuned bandpass filters using microstrip-line ring resonators", In IEEE MTT-S Int. Microw. Symp. Dig., pp. 411-414, 1986. 
[50] C. Hunter, J. D. Rhodes, “Electronically Tunable Microwave Bandpass Filters”, IEEE Trans. MTT, Vol. 30, No. 9, 1982.

[51] Makimoto M., Yamashita S., “Bandpass filters using parallel coupled stripline stepped impedance resonators”, IEEE Trans. Microw. Theory Tech., Vol. 28, No. 12, pp. 1413-1417, 1980.

[52] J. A. G. Malherbe, “Microwave Transmission Line Filters,” Artech House, 1979.

\section{BIOGRAPHIES OF AUTHORS}

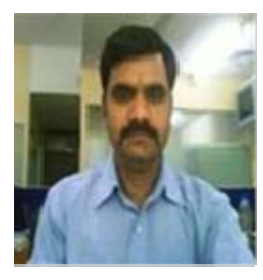

Rajinder Tiwari, received his M.Sc degree in Electronics Science from Jammu University, Jammu in 1998. M.Tech degree in Instrumentation Engineering from National Institute of Technology (NIT), Kurukshetra (Formerly, Regional Engineering College, Kurukshetra), Kurukshetra in 2002. He is pursuing $\mathrm{PhD}$ degree from Uttarakhand Technical University, Dehradun. Presently, he is working in the capacity of Assistant Professor in Department of Electrical \& Electronics Engineering, Amity University, Lucknow. He has published several research papers in the International and national Journals and Conferences with high repute. His areas of interest are Analog CMOS Circuits (VLSI), Embedded System Design, Industrial Automation System Design, Process Instrumentation and Control based Intelligent Systems, Digital Image Processing, Digital System Design. He is the life member of several professional bodies i.e. IETE, IET (U.K.), MRSI, UACEEE.

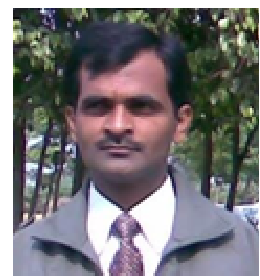

G R Mishra, received his $\mathrm{PhD}$ degree in Electronics from Faizabad University, faizabad in 2009. Presently, he is working in the capacity of Assistant Professor in Department of Electrical \& Electronics Engineering, Amity University, Lucknow. He has published several research papers in the International and national Journals and Conferences with high repute. His areas of interest are VLSI, Embedded System Design, Digital Image Processing, Microprocessor \& Microcontrollers, Digital System Design. He is the life member of several professional bodies i.e. IETE, IET (U.K.), MRSI. 